\title{
The effects of heat treatment on the electrochemical properties and corrosion of aluminium alloy AA8011 in an aqueous acid media
}

\author{
B. Okeoma Kelechukwu ${ }^{1, *}$, O. Owate Israel ${ }^{2}$, E. Oguzie Emeka ${ }^{3}$, \\ M. Mejeha Ihebrodike ${ }^{1}$, Nnanna Lebe ${ }^{4}$, Eze Joseph ${ }^{5}$ \\ ${ }^{1}$ Materials Science Group, Department of Physics, Federal University of Technology, \\ Owerri, Nigeria \\ ${ }^{2}$ Materials Science Group, Department of Physics, University of Port Harcourt, Nigeria. \\ ${ }^{3}$ Electrochemistry and Materials Science Research Unit, Department of Chemistry, \\ Federal University of Technology, Owerri, Nigeria \\ ${ }^{4}$ Material Science Group, Department of Physics and Electronics, Abia State Polytechnic, \\ Aba, Nigeria \\ ${ }^{5}$ Materials/ Electronics Group, Department of Physics/ Electronics, Federal Polytechnic, \\ Nekede Owerri, Nigeria \\ *E-mail address: bierechi@yahoo.com
}

\begin{abstract}
Effects of heat treatment and quenching regimen on the electrochemical corrosion behaviour of aluminium alloy AA8011 in $0.1 \mathrm{M} \mathrm{H}_{2} \mathrm{SO}_{4}$ was studied by open circuit potential, potentiodynamic polarization and electrochemical impedance spectroscopy measurements. Three different specimens (untreated/ control, air -quenched oven- quenched) were investigated. Polarization results show that all the specimens underwent active dissolution, with no distinctive transition to passivation, heat treatment was observed to shift the corrosion potential towards low anodic values and decreased the rates of anodic partial reactions of the corrosion process. Electrochemical investigations reveal that heat treatment techniques have positive impacts on the alloy as indicated in increase in charge transfer resistance, polarization resistance and decrease in double layer capacitance. These positive effects are attributed to decrease in mean defect size and increase in lattice distortion of the crystallites in the heat treated specimens of the alloy. Studies of X-ray diffraction (XRD) spectra, scanning electron microscopy (SEM) morphologies of control, air and oven quenched samples of AA8011 aluminium alloy indicate decrease in mean defect size of $18.97 \%$ and $40.44 \%$; increase in the lattice distortion of $11.07 \%$ and $20.04 \%$ for air and oven quenched specimens respectively.
\end{abstract}

Keywords: Heat treatment; Electrochemical Measurement; Double layer capacitance; Mean defect size; Lattice distortion

\section{INTRODUCTION}

Aluminium is very reactive with electrochemical potential of $-1.67 \mathrm{~V}$, but despite this, in oxygen containing environments (air and water) alumimium readily forms compact adhesive oxide layer immediately after fabrication [1]. Aluminium also has very low density, 
high thermal and electrical conductivities, possesses satisfactory mechanical and relatively good corrosion resistance [2-7]. Due to these excellent properties, the metal and its alloys have versatile applications in variety of domestic and industrial arena. In service, the metal and the alloys are exposed to myriad aggressive environments, where the materials undergo dissolutions. However, investigations into the corrosion behavior of aluminium have shown that it is stable within PH range of 4 and 9 [8]. This has been attributed to the compact but amphoteric oxide film that covers the material immediately after fabrication. This is why it dissolves readily in strong acidic and alkaline media, initiating the metal dissolution [9].

Aluninium alloy systems Al-Mn-Fe-Si are often used in heat exchanger system where they undergo series of heating and cooling sequences in a variety of aggressive environments, these undoubtedly affect the strength and electrochemical stability of the alloys exposed to various environments. Not only that exposure to the varied temperatures causes changes in second phases formed, but also the thickness of the compact oxide layer is increased, Shimizu et al, [10] observed. In the course of exposure to high temperatures, second phases are often formed or dissolved; the type, size, and nature depend on the heat treatments the materials are subjected to. For example, Borodiak et al. [11], in discussing the character of matrix dissolution in aluminium, identified the presence of harmful and un-harmful inter-metallic particles since the hazardous particles do not dissolve during homogenization treatment. Further, Li and Arnberg, [12], observed a large strain field around $\mathrm{Al}_{6}(\mathrm{Mn}, \mathrm{Fe})$ intermetallic particle due to semi-coherence in orientation between the particle and the matrix. And also heat treatment decreases the ratio of $\mathrm{Fe}$ and $\mathrm{Mn}$ of the intermetallic particles as other particles are formed [13]. This results from the segregation of Mn particles during heat treatment so as to obtain a desirable particle size, [14]. The result of the redistribution of the constituents of the intermetallic particle is a change in the electrochemical character of the phases, which is exhibited in anodic or cathodic nature of the materials.

The difference in potential between the phases and matrix could normally give rise to galvanic cell formation [15-16]. This could either hinder or accelerate the corrosion rate depending on the nature of interaction of the material/ phases with the environment. Accordingly, the present study investigates the impacts of heat treatment on the electrochemical corrosion behaviour of aluminium alloy AA8011 in $0.1 \mathrm{M} \mathrm{H}_{2} \mathrm{SO}_{4}$. Attempts have been made to assess the character of phase constituents of the different specimens by Xray diffraction (XRD) and scanning electron microscopy (SEM).

\section{EXPERIMENTAL}

\section{1. Material Preparation}

Aluminium alloy AA8011 of compositions (Si- 0.22. Fe- 0.57, Cu- 0.02; Mn- 0.06, Al99.06; others the balance) used in the study was obtained from First Aluminium PLC Port Harcourt Nigeria. The heat treated specimens were subjected to a temperature of $150{ }^{\circ} \mathrm{C}$ in a furnace for 1 hour and subsequently divided into two sets: one set was removed from the furnace and allowed to cool in open air (air quenched), while the other set (oven quenched) was left in the furnace to cool at a rate of $0.2^{\circ} \mathrm{C} / \mathrm{hr}$. in order to mimic the gradual cooling sequence found in heat exchanger chambers. The as received or unheated, air quenched and oven quenched samples were machined into coupons of dimensions: $1.5 \mathrm{~cm}$ by $1.5 \mathrm{~cm}$, wet polished with silicon carbide abrasive paper (from grade \# 200 to 1200) degreased in acetone, rinsed with distilled water and dried in warm air. These were subsequently sealed with epoxy resin in such a way that only one square surface of area $1.0 \mathrm{~cm}^{2}$ was left uncovered. 


\section{2. Material Characterization}

Structural characteristics of the as received (unheated) AA8011 and heat treated and quenched specimens were analyzed by X- ray diffraction (XRD, Xpert- Pro.) using $\mathrm{Cu} \mathrm{K} \alpha$ radiation as well as by scanning electron microscopy (SEM), Shimadzu. SSX-550). XRD measurements were undertaken to enable verification of the phase constitution before and after heat treatment/ quenching, SEM imaging was used to identify surface defects (including inhomogeneities and porous intensity arising from the different heat treatments/ quenching.

\section{3. Electrochemical Measurements}

Electrochemical measurements were conducted in a conventional three electrode cell using VERSASTAT 400 Complete DC Voltammetry and corrosion system, with V3 Studio software. A platinum foil was used as counter electrode and standard calomel electrode (SCE) as reference electrode. The later was connected via a Luggin's capillary. The test electrolyte was $0.1 \mathrm{M} \mathrm{H}_{2} \mathrm{SO}_{4}$, prepared from analytical reagent grade concentrated acid using distilled water. Measurements were performed in aerated and unstirred solution at the end of $1 \mathrm{~h}$ of immersion at $30^{\circ} \mathrm{C}$, impedance measurements were made at potentials $\left(\mathrm{E}_{\mathrm{Corr}}\right)$ over a frequency range of $100 \mathrm{kHz}-10 \mathrm{mHz}$, with a signal amplitude perturbation of $5 \mathrm{mV}$. Potentiodynamic polarization studies were carried out in the potential range -1.0 and $1.7 \mathrm{~V}$ versus the corrosion potential at a scan rate of $1 \mathrm{mVs}^{-1}$. Each test was run in triplicate to verify the reproducibility of the systems.

\section{RESULTS AND DISCUSSION}

\section{1. Structural Analysis}

\section{1. 1. XRD spectra}

Fig. 1 shows the XRD pattern of the unheated/ control, air quenched and oven quenched specimens of AA8011. It is easily seen that all the samples display distinct, sharp and narrow peaks, signifying high crystalline nature of the alloy AA8011, [17]. The mean defect size $\left(\mathrm{L}_{\mathrm{C}}\right)$ was determined by using Short and Walker's method applying the expression [18] (eq. 1):

$$
L_{c}(n m)=57.3 K \lambda / \beta \cos \theta \quad 1
$$

where $\mathrm{K}$ is Scherrer's constant (0.89), $\beta$ is the peak width of maxima at half height, $\theta$ is diffracting angle. From the fig. 1, it can be observed that the control has the highest intense peaks, when compare with the heated samples. 


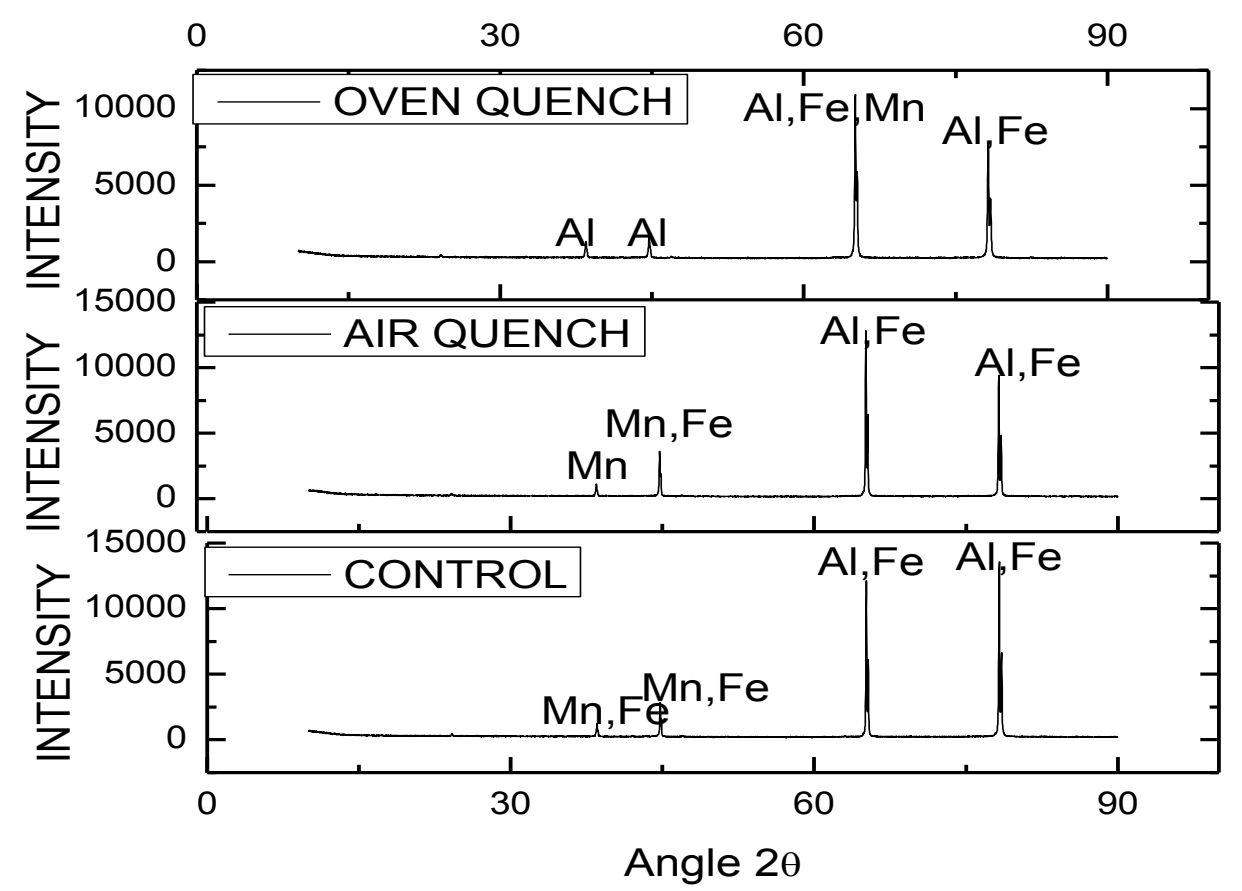

Figure 1. The XRD Spectra of control, air, and oven quenched specimens of AA8011.

However, the air quenched sample's peaks are higher than the oven quenched samples. This observation collaborates with the calculations on mean defect size and its value for control is the highest. Since the mean defect size is known to be a function of crystallinity [18], therefore decrease in the mean defect size as observed in the heat treated sample implied that heat treatment caused decrease in crystallinity. Further the effects of heat treatment can be elucidated by considering the degree of lattice distortion of the crystallites in the samples. The lattice distortion (e) is given by Fewster, [19]( eq. 2)

$$
e=\frac{\beta \operatorname{strain} \operatorname{Cotan} \theta}{4}
$$

where $\beta$ strain is the integral breadth contribution due to strain on the different phases on each of the samples. The calculated values of lattice distortion are given in Table 1. From the table, the degree of lattice distortion on the phases increased in the heat treated samples, the oven quenched specimen being higher than that of air quenched specimen. It is obviously observed that as the mean defect size decreases, the lattice distortion increases. The total percentage reduction in mean defect size is $18.97 \%$ for air quenched and $40.44 \%$ for oven quenched. The total percentage increase in lattice distortion is $11.07 \%$ and $20.04 \%$ for air and oven quenched specimens respectively. It can therefore be concluded that heat treatment caused decrease in mean defect size; hence decrease in crystallinity and this may have resulted from the increase in the lattice distortion observed in the heat treated samples. 
Table 1. The Intermetallic particles, Mean defect size $\mathrm{L}_{\mathrm{C}}$, Lattice distortion for control, and heat treated sample of AA8011.

\begin{tabular}{l|ccc|ccc|}
\hline Particles & \multicolumn{3}{c|}{ Mean defect Size Lc $(\mathbf{n m})$} & \multicolumn{3}{c|}{ Lattice distortion } \\
& Control & Air quenched & Oven Quenched & Control & Air quenched & Oven quenched \\
Mn & 779.58 & 1165.50 & 389.75 & 0.0781 & 0.1772 & 0.1566 \\
FeMn & 2564.03 & 1577.25 & ------- & 0.1741 & 0.0867 & ------- \\
AlFe & 3097.01 & 2476.63 & 1182.48 & 0.1138 & 0.1427 & 0.0692 \\
AlFeMn & --------- & --------- & 1186.67 & --------- & --------- & 0.0805 \\
Al & --------- & -------- & 1077.14 & -------- & ------- & 0.1330 \\
Total & 6440.62 & 5219.38 & 3836.04 & 0.3660 & 0.4065 & 0.4393
\end{tabular}

The corrosion behaviours of the heat treated specimens can be related to the features of the intermetallic particles arising from the heat treatment as illustrated in the XRD spectra (Fig. 1). The corrosion behaviours of the heat treated samples can be better explained by the fact that the comparatively large and less harmful particles result from the heat treatment and quenching processes. These provide low population of corrosion sites as well as low volume grain boundaries which reduce corrodent attack and corrodent transport to the alloy surface. It is possible to conclude that the larger lattice distortion that resulted from the heat treatment aids to increase the corrosion resistance of the AA8011 in the media under consideration.

\section{1. 2. SEM Morphological images}

SEM micrographs of unheated, air quenched, and oven quenched specimens are illustrated in Fig. 2. The unheated specimens (2a) have many disperse white spots, darks patches, and grey strands; all these are within a light grey background. Figure (2b) shows the air quenched specimen, which contains spreads of white spots, with some green strands, within dark grey background. Figure (2c) shows white spots, with some dispersed but spread white patches, and some cloudy grayish patches. From these specimens, it is clear that heat treatment caused increase in spread of some of the white spots and also caused blurring of the background. This corresponds to the increase in lattice distortion as found in the heat treated samples.

Comparison of the heat treated samples shows that the oven quenched sample has both white spots and spread white patches, while the air quenched sample that contains $\mathrm{Al}_{6}(\mathrm{FeMn})$ particles shows spread of white particles which Li and Arnberg [12] described as semicoherent in orientation with $\mathrm{Al}$ matrix.

From the observations, one may deduce that heat treatment affected the morphology of AA8011 and the procedure of heat treatment goes to bring distinguishing features. The observations made in the SEM are in line with the features noticed in the XRD spectra and these further buttresses the changes in the calculations of the mean defect size and lattice distortion of the different intermetallic constituents of the studied samples. 


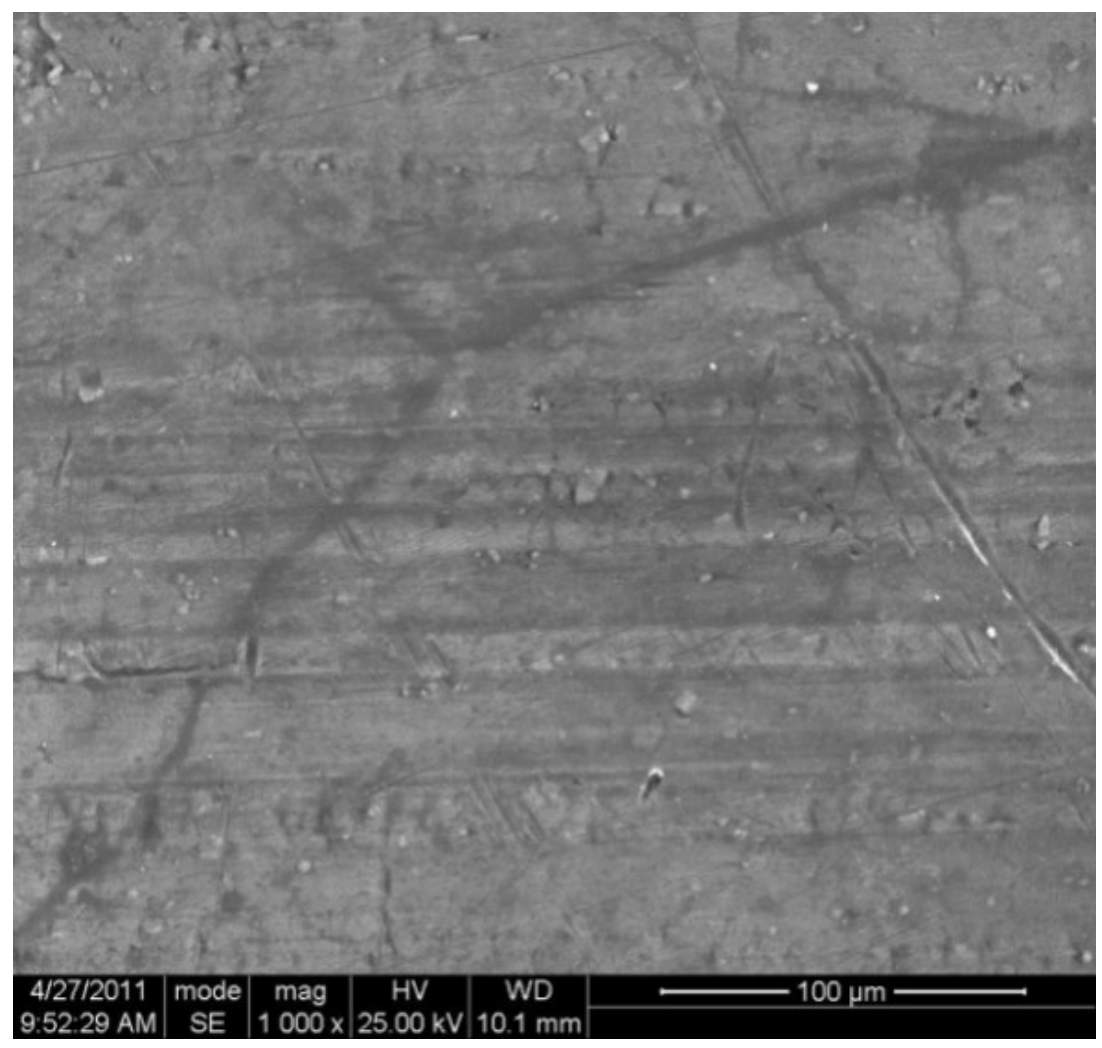

(a)

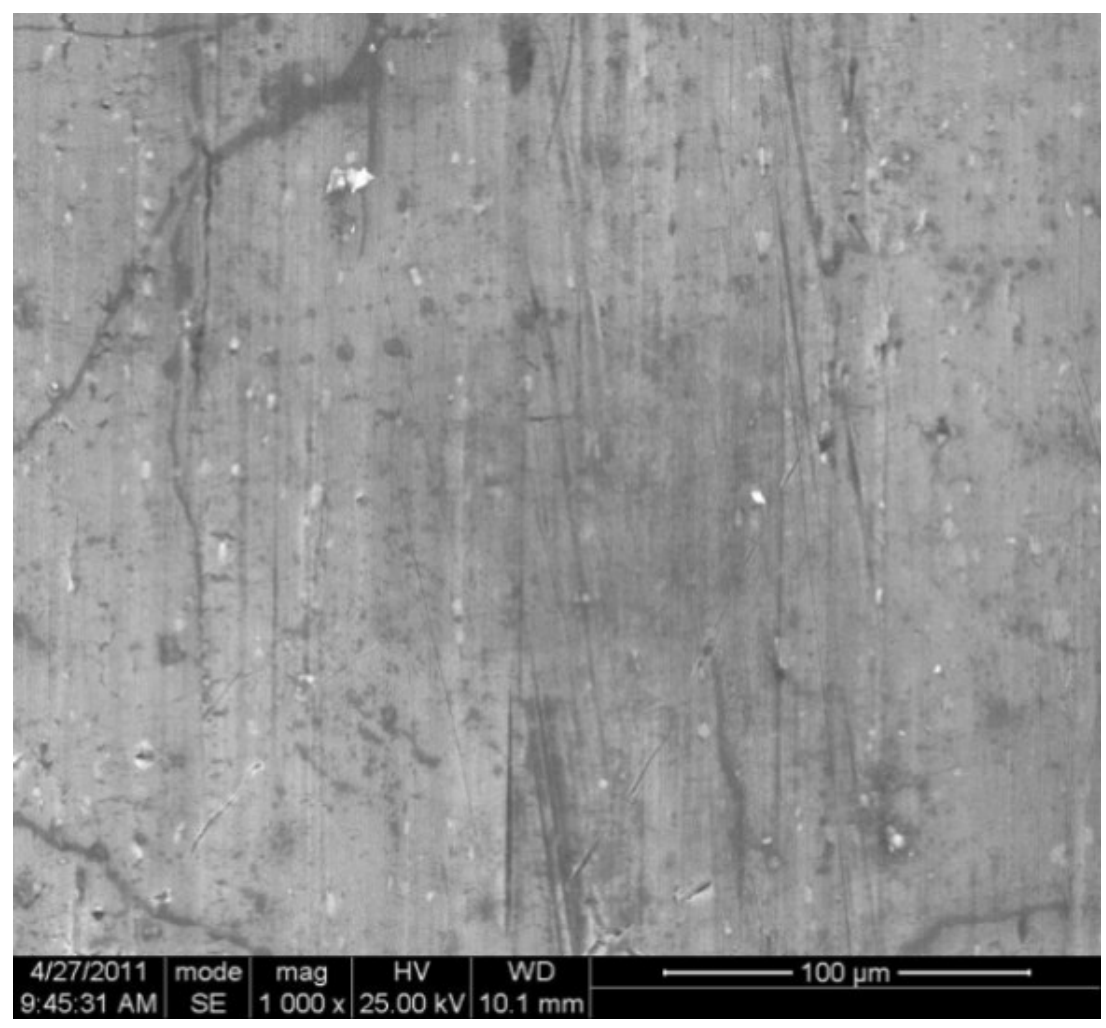

(b) 


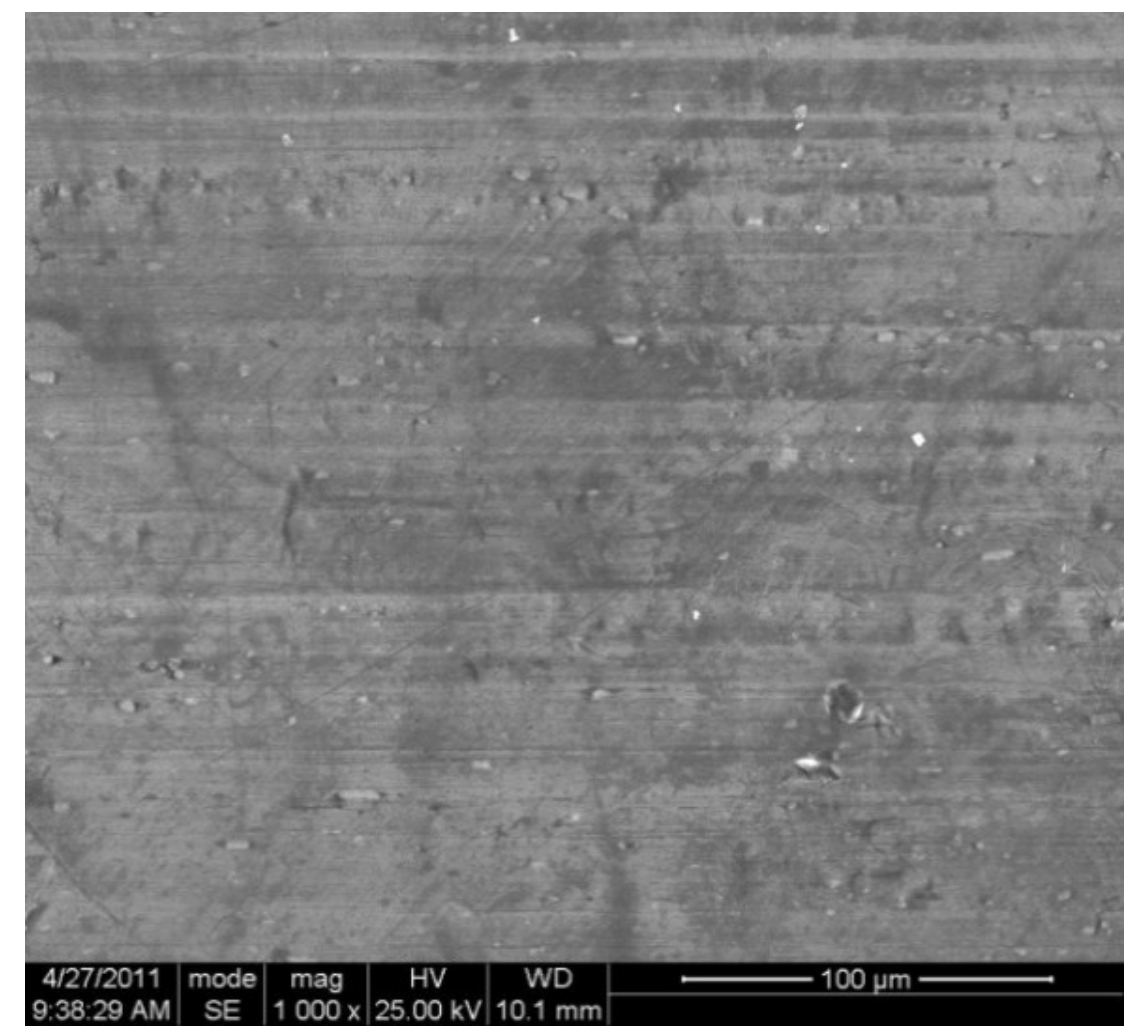

(c)

Figure 2. The SEM morphologies of (a) control (b) air quenched and (c) oven quenched samples of AA8011 aluminium alloy.

\section{2. Electrochemical Spectroscopy}

\section{2. 1. Open circuit potential measurements.}

The variation of the open circuit potential $\left(\mathrm{E}_{\mathrm{ocp}}\right)$ with time for AA8011 specimen in 0.1 $\mathrm{M} \mathrm{H}_{2} \mathrm{SO}_{4}$ solution is shown in Fig. 3. The $\mathrm{E}_{\text {ocp }}$ of all the specimens show similar changes with time. They are almost constant at a particular potential between the time intervals of 0 and about $2500 \mathrm{~s}$, before decreasing all at different rates.

The $\mathrm{E}_{\mathrm{ocp}}$ for heat treated specimens shifted to more negative values, with the oven quenched samples shifting more, and since high insulating film is associated with more cathodic potential. It can be concluded that the heat treatment caused increase in oxide film thickness. This means that the oven quenched specimen has higher insulating oxide film than the air quenched specimen.

From the observations and calculations on the lattice distortion, it is possible to suggest that the large lattice distortions in the heat treated specimens offer large area for the insulating oxide films to be formed. The hardness or porosity of the oxide film depends on the techniques adopted for the heat treatment. 


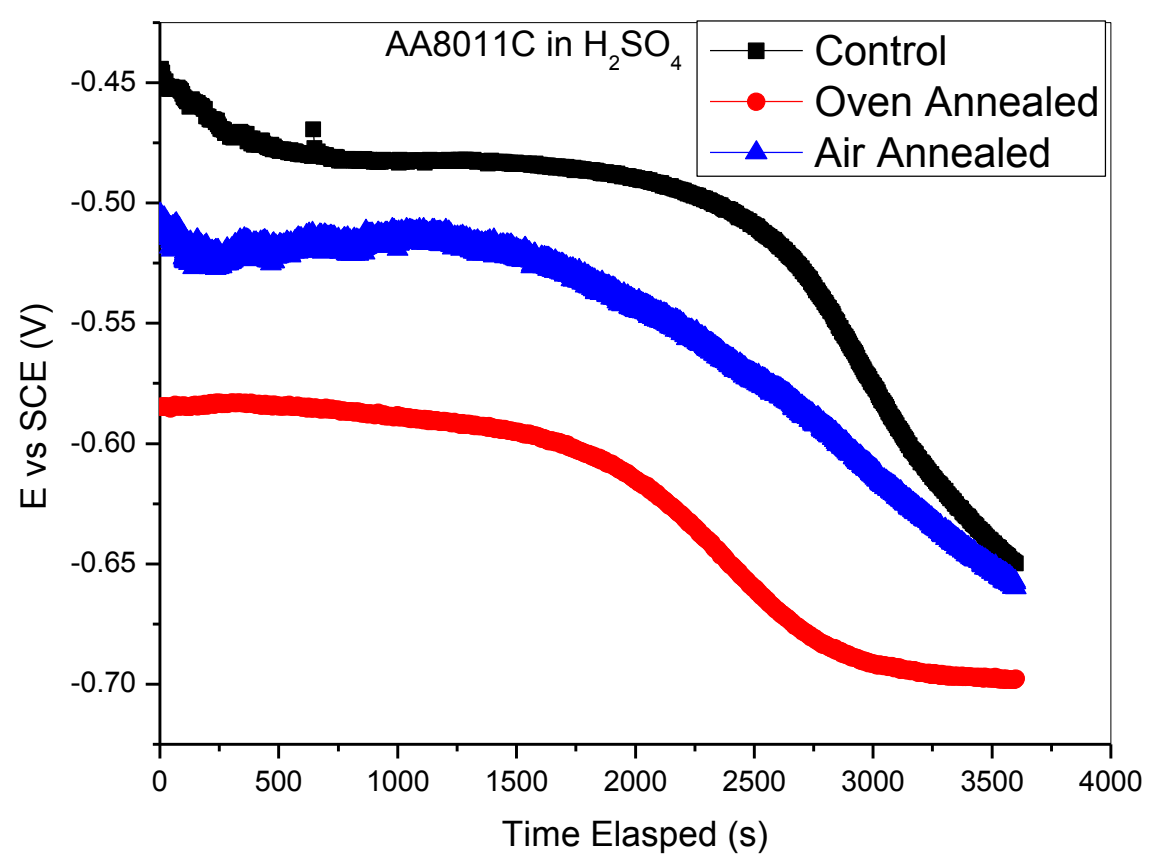

Figure 3. The open circuit potential profiles for control, air and oven quenched specimens of aluminium alloy AA8011 in sulphuric acid solution.

\section{2. 2. Potentiodynamic Polarization Measurements}

The potentiodynamic polarization curves for control, air quenched and oven quenched specimens of AA8011 in $0.1 \mathrm{M} \mathrm{H}_{2} \mathrm{SO}_{4}$ are presented in Fig. 4, and the corresponding electrochemical parameters shown in Table 2. All the three samples exhibit active dissolution with no distinctive transition to passivation up to $1.7 \mathrm{~V}$ versus SCE. The similarity of the polarization curves for the three specimens suggests comparable corrosion mechanism. It is obvious that heat treatment has positive influence on the polarization behavior of AA8011 in $0.1 \mathrm{M} \mathrm{H}_{2} \mathrm{SO}_{4}$ acid environment. It decreased the anodic current density, while cathodic current densities and the corrosion potential $\mathrm{E}_{\text {corr }}$ for all the specimens have the same values. The shift of the anodic arm of the heat treated specimens to lower current density points to the fact that heat treatment caused increase in the polarization resistance. These positive effects of heat treatment may be attributed to the formation of less harmful intermetallic $\mathrm{Al}_{6}(\mathrm{FeMn})$ in the oven quenched sample, which are semi-coherent in orientation with the matrix and FeMn for air quenched specimen and reduction in the mean defect size of AlFe in the heat treated samples as shown in Table 1. It is possible to suggest that increase in polarization resistance of the heat treated specimens may have been mainly due to reduction in mean defect size for the heat treated samples. Further the presence of $\mathrm{Al}$ and $\mathrm{Al}_{6}(\mathrm{FeMn})$ crystallites in the oven quenched sample gives credence to the increase in polarization resistance. From the Tables 1 and 2, it is possible to suggest that increase in polarization resistance may have been due to large lattice distortion of AlFe, as observed in the heat treated samples. In Table 2 the value of corrosion current density of the oven quenched sample is higher than the corrosion current densities of air quenched specimen, the difference 
may be attributed to different quenching techniques employed and their effects on Tafel constants. In conclusion, the increase in polarization resistance of the heat treated samples may be attributed to decrease in mean defect size and increase in lattice distortion which is observed in the heat treated samples. The observation further suggests that decrease in crystallinity results to increase in corrosion resistance.

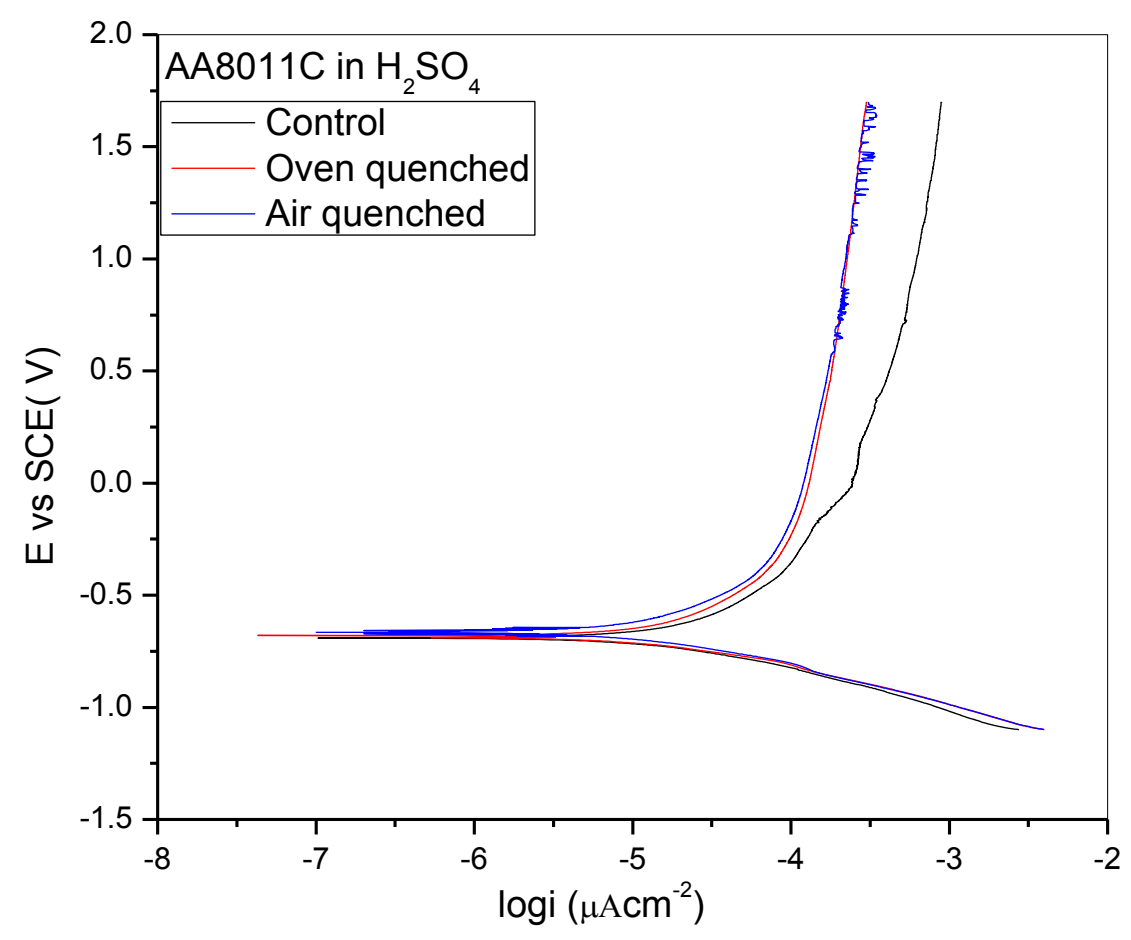

Figure 4. The potentiodynamic polarization profiles for control, air and oven quenched samples of AA8011 in sulphuric acid solution.

Table 2. The Corrosion Potential $\mathrm{E}_{\text {corr }}$, Current densities $\mathrm{I}_{\text {Corr }}$, and polarization Resistance, $\mathrm{R}_{\mathrm{p}}$ of the control, air quenched and oven quenched specimens of AA8011 exposed to $0.1 \mathrm{M} \mathrm{H}_{2} \mathrm{SO}_{4}$ acid solution.

\begin{tabular}{|c|c|c|c|}
\hline & & & \\
Parameter & Control & Air quenched & Oven quenched \\
$\mathrm{E}_{\text {Corr }}(\mathrm{V})$ & -0.6906 & -0.6804 & -0.6637 \\
Icorr $\left(\mu \mathrm{A} / \mathrm{cm}^{-2}\right)$ & 85.39 & 48.78 & 319.52 \\
$\mathrm{R}_{\mathrm{p}}(\mathrm{k} \Omega)$ & 6.10 & 27.18 & 13.23 \\
& & & \\
\hline
\end{tabular}




\section{2. 3. Impedance Measurements}

The electrochemical impedance spectra were measured at open circuit potential for the control, air quenched and oven quenched samples of AA8011 in $0.1 \mathrm{M} \mathrm{H}_{2} \mathrm{SO}_{4}$ acid environments. The obtained impedance responses are presented in Fig 5. All the specimens display similar impedance features; each Nyquist plot is characterized by a single depressed capacitive semicircle from high to intermediate frequencies followed by a low frequency inductive arc. The capacitive loop can be attributed to charge transfer processes associated with the effects of double layer capacitance and its diameter is related to the charge transfer resistance $\left(\mathrm{R}_{\mathrm{ct}}\right)$ at the metal/solution interface, while the inductive loop probably results from adsorbed intermediate product [8].

The corrosion behaviour of the heat treated specimens can be related to the features of the intermetallic particles arising from the heat treatment as illustrated in the XRD spectra (Fig. 1). The corrosion behaviour of the heat treated samples can be better explained by the fact that the comparatively large and less harmful particles result from the heat treatment and quenching processes. These provide low population of corrosion sites as well as low volume grain boundaries which reduce corrodent attack and corrodent transport to the alloy surface.

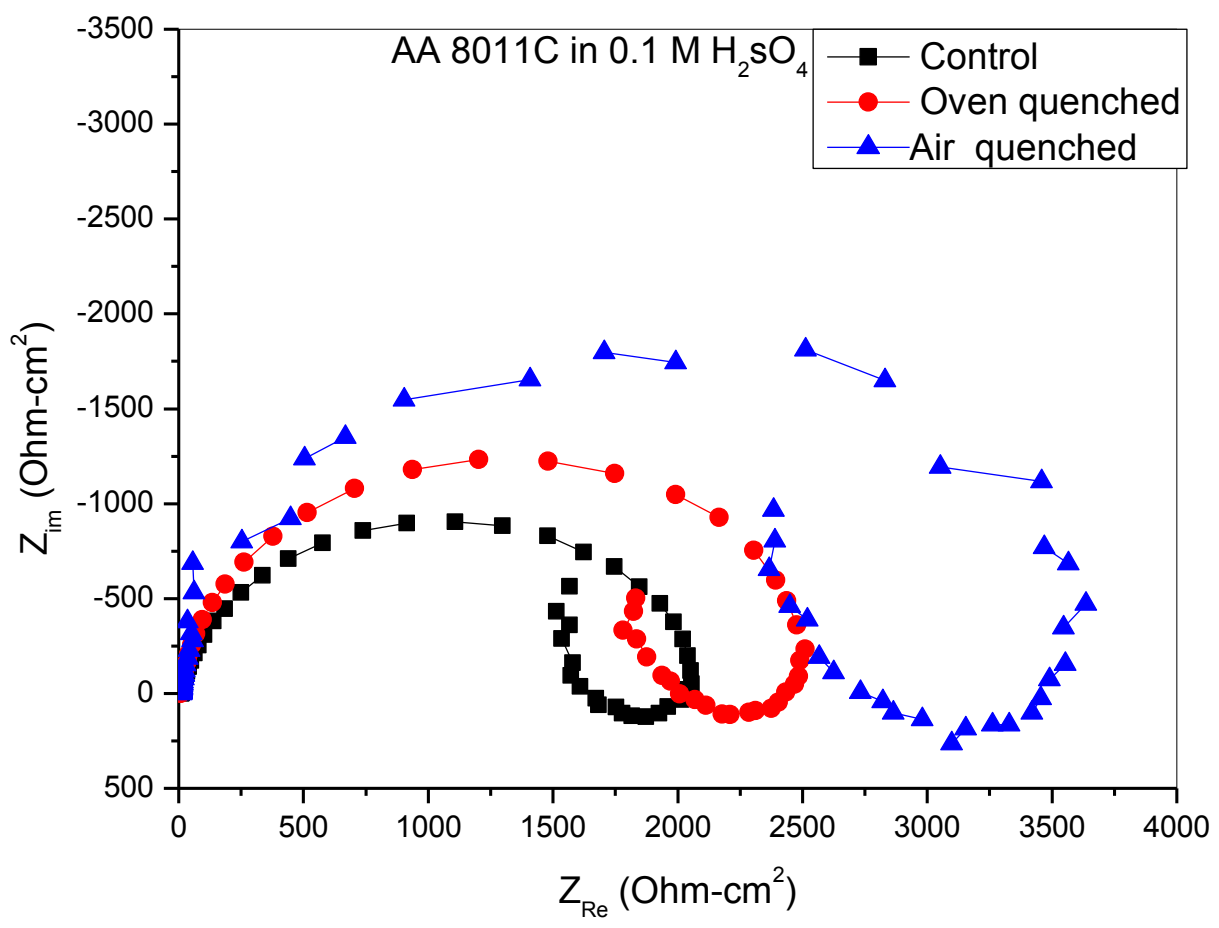

Figure 5. The electrochemical Impedance spectra for control, air and oven quenched specimens of AA8011 in acid solution of sulphuric acid.

The Nyquist plots clearly indicate that heat treatment caused increase in the diameter of the capacitive arc, hence the $\mathrm{R}_{\mathrm{ct}}$ which corresponds to an increase in the corrosion resistance of AA8011 in $0.1 \mathrm{M} \mathrm{H}_{2} \mathrm{SO}_{4}$ solution. This effect is more pronounced in air quenched sample and points toward low corrosion susceptibilities of the heat treated samples in the sulphuric acid medium. The value of charge transfer resistance increased in the order control $<$ oven quenched $<$ air quenched samples. This agrees with the trend of corrosion resistance 
predicted by the polarization data shown in table 2. But comparing the obtained value with those observed in another variant of AA8011 Okeoma, et al. [20] in which the charge transfer resistance increased in order control $<$ air quenched $<$ oven quenched samples.

It may therefore be misleading to draw conclusion on the effect of heat treatment on the impedance spectra, but the variation in the spectra maybe attributed to the type of intermetallic particles present, which is a result of heat treatment the alloy was subjected to. To obtain the numerical values of the various impedance parameters presented in table 3 , the impedance spectra were analyzed by fitting into Fig. 6, equivalent circuit $R_{s}\left(Q_{R_{c t}}\left(R_{L} L\right)\right)$.

$\mathrm{R}_{\mathrm{s}}$ is the solution resistance, which is the uncompensated resistance between the working electrode and the reference electrode; $\mathrm{R}_{\mathrm{ct}}$ is the leakage resistance that represents the charge transfer resistance associated with the constant phase element (CPE) Q, which is used to model the deviation from an ideal capacitor.

These are in parallel with $\mathrm{R}_{\mathrm{L}}$, which is the resistance offered to the migrating ions in the solution that manifested in the magnetic fields with its associated series inductance L, which becomes dominant within a certain frequency range for a particular specimen, Okeoma, et al [21].

Table 3. Simulated values of the various parameters for control, air quenched and oven quenched samples of AA8011 in $\mathrm{H}_{2} \mathrm{SO}_{4}$ acid solution fitted in Figure 6.

\begin{tabular}{llll} 
Parameter & Control & Air quenched & Oven quenched \\
$\mathrm{R}_{\mathrm{s}}(\Omega)$ & 10.84 & 11.18 & 9.19 \\
$\mathrm{CPE} \mathrm{Qx} 10^{-5}$ & 1.611 & 0.909 & 1.006 \\
Ferquency, $\mathrm{n}$ & 0.9073 & 0.9554 & 0.9550 \\
$\mathrm{R}_{\mathrm{ct}}\left(\Omega \mathrm{cm}^{-2}\right)$ & 2100.0 & 3755.0 & 2566.0 \\
$\mathrm{~L}\left(\mathrm{mHcm}^{-2}\right)$ & 6847 & 7315 & 7247 \\
$\mathrm{R}_{\mathrm{L}}\left(\Omega \mathrm{cm}^{-2}\right)$ & 8605 & 11060 & 9801 \\
$\mathrm{C}_{\mathrm{dl}} \mathrm{X} 10^{-5}\left(\mathrm{Fcm}^{-2}\right)$ & 1.140 & 0.776 & 0.848 \\
$\mathrm{Z}_{\text {imp max }}\left(\Omega \mathrm{cm}^{-2}\right)$ & 900.0 & 1880.0 & 1231.1 \\
$\mathrm{Z}_{\mathrm{remax}}\left(\Omega \mathrm{cm}^{-2}\right)$ & 2050 & 3545 & 2450 \\
$\mathrm{~F}_{\max }(\mathrm{Hz})$ & 6.31 & 7.9 & 5.0 \\
\hline
\end{tabular}




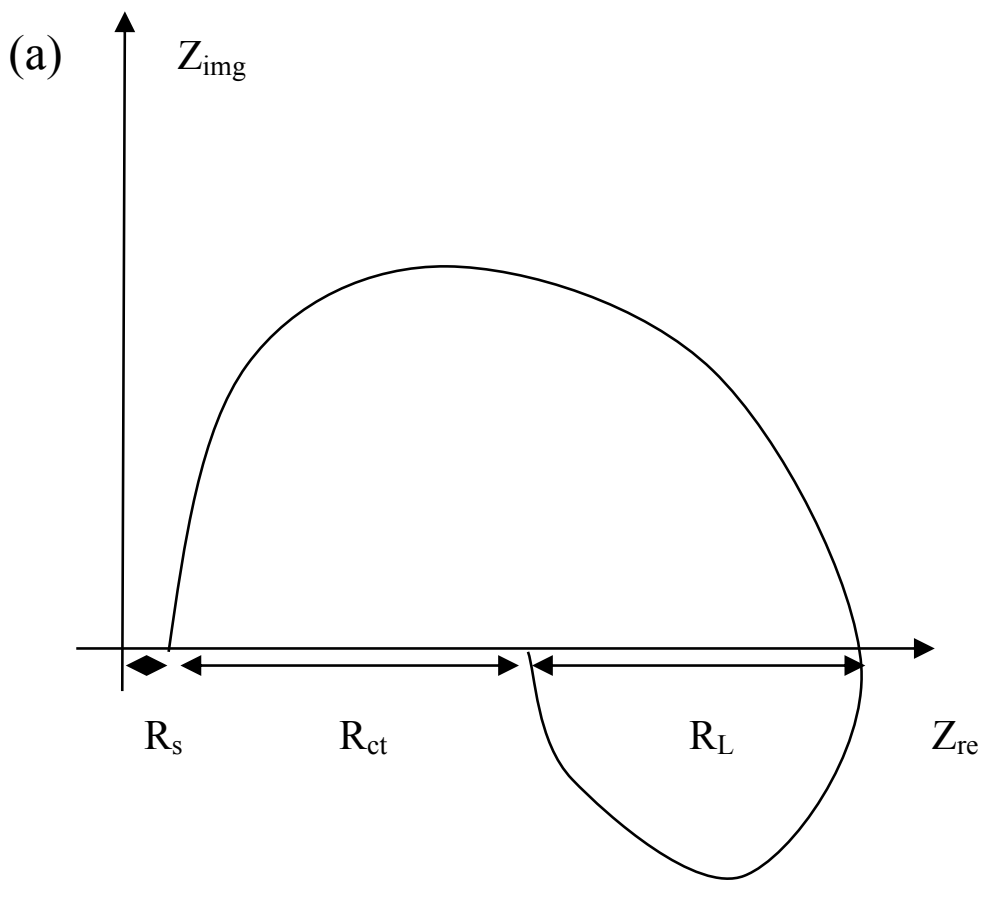

(b)

Q

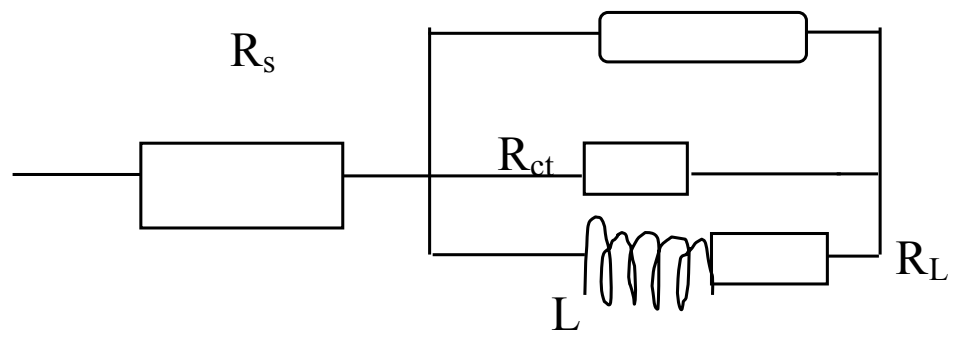

Figure 6. The model (a) impedance spectra and (b) simulated impedance circuit used to analyze the experimental data for control, air quenched and oven quenched specimens of AA8011 exposed to 0.1 $\mathrm{M} \mathrm{H}_{2} \mathrm{SO}_{4}$.

From Fig. 6b, the total impedance of the circuit can be calculated using eq (3-6)

$$
\begin{aligned}
& Z_{L}^{-1}=\frac{R_{L-j \omega L}}{R_{L}^{2}-(\omega L)^{2}} \\
& Z_{C P E}^{-1}=Q(j \omega)^{n}
\end{aligned}
$$


The resultant impedance $\mathrm{Z}$ is given by

$$
\begin{gathered}
Z_{\text {tot }}^{-1}=Z_{L}^{-1}+Z_{C P E}^{-1}+R_{C t}^{-1} \\
Z_{t o t}=R_{\mathrm{s}}+\left\{\frac{R_{c t}\left(R_{L}-(j \omega)+\left[Q ( j \omega ) ^ { n } \left(R_{L}^{2}+(\omega L)^{2} R_{c t}+R_{c t}\left(R_{L}-j \omega L\right)\right.\right.\right.}{\left[R_{L}^{2}+(\omega L)^{2}\right] R_{c t}}\right\}^{-1}
\end{gathered}
$$

where $Z_{C P E}$ is the impedance due to the constant phase element, and $Z_{L}$ is the resultant impedance due to series combination of inductance $\mathrm{L}$ and resistance $R_{L}$. In the complex impedance plot of Fig $6 \mathrm{~b}$, the value of charge transfer resistance $R_{c t}$ represents the intersection point of the low frequency semicircle on the real axis, for $\omega \rightarrow 0$. In general, the value of this intersection may be used to obtain the apparent ac polarization resistance $R_{p}$

$$
R_{p=} \lim _{\omega \rightarrow 0} Z_{R}
$$

From the results presented in table 3, the effects of heat treatment are very pronounced, the values of CPE, Q decreased, and the air quenched being the least. The non- idealilty in capacitive behavior $\mathrm{n}$ increased in the heat treated specimen, with air quenched being the highest. Other parameters: $R_{c t}, R_{L}$, and $\mathrm{L}$, all increased in the heat treated specimens, with air quenched specimen being highest in each case. These high resistance values give credence to the low current densities observed in the potentiodynamic polarization. The capacitance at maximum imaginary impedance determined by

$$
\mathrm{C}=\left[\omega\left(\mathrm{Z}_{\mathrm{imp}}\right) \mathrm{R}_{\mathrm{ct}}\right]^{-1}
$$

decreases in the heat treated specimens, oven quenched being the least. Where $Z_{\text {imp }}$ is the maximum imaginary impedance and $\omega$ is the angular frequency at the maximum impedance. From the above information, it implies that the thickness of the oxide film increased for the heat treated samples. This indicates that the heat treatment may have caused the growth of oxide layers and the corrosion products that aided the blockage of active sites which translated to the high impedance in the heat treated samples of AA8011 within $0.1 \mathrm{M} \mathrm{H}_{2} \mathrm{SO}_{4}$. To support this result, double layer capacitance which is used as index of corrosion rate since it is proportional to it Abd El Rehim, et al [22]. This is calculated using equation (9) below:

$$
C_{d l}=\left[Q R^{1-n}\right]^{1 / \mathrm{n}}
$$

where $\mathrm{Q}$ is the constant phase element, $\mathrm{R}$ is the resistance associated with it, and $\mathrm{n}$ is the frequency that measures the degree of inhomogeneity. The calculated value of the double layer capacitance for control, oven and air quenched specimens show that the heat treatment caused the double layer capacitance to decrease. The value for air quenched is smaller than for oven quenched sample. The low values of double layer capacitance are evidences that heat treatment caused the alloy AA8011 to develop increase in the thickness of the insulating oxide layers which is larger for air quenched sample than oven quenched specimen. This is true when Helmholtz model ( $C_{d l}=\frac{\varepsilon A}{\delta}$ ) is assumed, the increase in double layer capacitance implies decrease in oxide film thickness since the dielectric constant is not expected to change much, where A is area of electrode exposed which is the same for all the systems, and 
$\delta$ is the thickness. These results and deductions support the XRD and SEM data presented above. These positive effects of AA8011 in $0.1 \mathrm{M} \mathrm{H}_{2} \mathrm{SO}_{4}$ results not only from the increase in thickness of the oxide layer, but also in the precipitations of the intermetallic particles on heating which has larger lattice distortion.

The main issue however, is not only the increase in the thickness but how compact and the porosity of the oxide layer which determines the susceptibility of the oxide layer to corrosion. Comparing the effects of heat treatment on alloys of AA3003 Okeoma et al. [21], and a different composition of AA8011 Okeoma, et al, [20] in $0.1 \mathrm{M} \mathrm{H}_{2} \mathrm{SO}_{4}$ and the present report, it is evidence that AA8011 is superior to AA3003, this adds to the observations made by Delijic et al [23] on the mechanical properties. The positive effects of heat treatment on this AA8011 alloy in the acid environment open up further opportunity to understand the properties of the material and hence usher in another sphere to the application of the alloy.

\section{CONCLUSIONS}

The electrochemical properties of unheated/ control and heat treated specimens of aluminium alloy AA8011 in $0.1 \mathrm{M} \mathrm{H}_{2} \mathrm{SO}_{4}$ acid solution were studied after the XRD and SEM measurements of the samples were taken, it can be concluded that:

- The XRD profiles showed sharp, narrow, high, peak values for all the alloy samples, indicating high crystallinity of the AA8011 alloy samples.

- The heat treatment caused formation of less harmful crystallite $\mathrm{Al}_{6}(\mathrm{FeMn})$ for oven quenched sample and decrease in the mean defect size of the harmful crystallite $\mathrm{AlFe}_{3}$, and this resulted to overall decrease in the mean defect sizes of $18.97 \%$ and $40.44 \%$ for air and oven quenched specimens respectively.

- The heat treatment caused increase in lattice distortion of $11.07 \%$ and $20.04 \%$ for air and oven quenched samples respectively.

- The reduction in mean defect size and increase in lattice distortion translated to increase in corrosion resistance.

- The OCP, PP, and EIS all buttress the effects of heat treatment on the corrosion resistance of AA8011 in the acid environment; this is evidence in lower current densities, higher polarization resistance, higher capacitive loops and larger values of simulated parameters.

- The increase values of the thickness of the oxide layer of the heat treated specimen might have contributed to the blockage of active sites, which resulted to lower values of double layer capacitance and hence higher corrosion resistance in the heat treated samples.

- The outcome of this research is an eye opener to the usage of the AA8011 in the service environment of $0.1 \mathrm{M} \mathrm{H}_{2} \mathrm{SO}_{4}$ acid environment.

\section{References}

[1] M. Pourbaix, NACE Cebelcor, (1974) Huston, USA

[2] M. A. Amin; Q. Mohsen G. A. M. Mersal, Port. Electrochim Acta 28(2) (2010) 95-112.

[3] C. M. A. Bret, I. A. R. Gomes, J. P. S. Martins, J. Appl. Electrochem. 24(1994) 1158. 
[4] R. Roslica, W. B. Wan Nik, H. B. Senin, J. Mater. Chem. Phys. 107 (2008) 281-288.

[5] G. A. Capuano, W. G. Daven, J. Electrochem. Soc. (1971) 1688.

[6] P. Fellener; M. C. Paucivova, K. Mataisovski, Surf. Techn. 14 (1981) 101.

[7] C. C. Yang, Mater. Chem. Phys. 37 (194) 355.

[8] M. Metskos-Hukovic, R. Babic, Z. Grubac, J. Appl. Electrochem. 32 (2002) 35-41.

[9] C. Vergel, Corrosion of aluminium, Elservier, USA, 2004, 100-106.

[10] K. Shimizu, R. C. Furneaux, G. E. Thomson, G. C. Wood, A. Gotoh, K. Kobayashi, Oxidation of Al 35(5/6) (1991) 427.

[11] M. Borodiak, P. F. Pinheiro, M. Paes, Light Metals (2012) edited Carlos. E.S. TMS. 455-460.

[12] Y. J. Li, L. Arnberg, Mater. Sci. Engn. A (2003) 347.

[13] D. T. L. Alexander, R. G. Hamerton, H. Cama, A. L. Greer, Light Metals (2002) edited. Wolfgang S.

[14] G. Wang, H. Jiao, Transaction of Nonferous, Met. Soc. China 21 (2011) 1193-1198.

[15] V. S. Sinyavski, Prot. Met. 37 (2001) 469.

[16] R. G. Buchheit, L. P. Montez, M. A. Martinez, J. Michael, P. F. Halva, J. Electrochem. Soc. 146 (1994) 4424.

[17] G. Rubi, O. P. Modi, A. K. Jha, I. B. Singh, Ind. J. Chem. Techn. 16 (2008) 216-220.

[18] R. Hussain, R. Qadeer, Turk. J. Chem. 24 (2000) 177

[19] P. F. Fewster, Rep. Prog. Phys. 59 (1996) 1339.

[20] K. B. Okeoma, I. O. Owate, E. E. Oguzie, I. M. Mejeha, Intern. J. Mater. Chem. 2(4) (2012) 178- 184.

[21] K. B. Okeoma, I. O. Owate, E. E. Oguzie, I. M. Mejeha, Global Advances and Researches: Journal Chem. Mater. Sci. 3 (2012) 055- 062.

[22] S. S. Abd El Rehim, H. H Hassan, M. A. Amin, Mater. Chem. Phys. 78 (2002) 337- 348 .

[23] K. Delijic, V. Asanovic, D. Radonjic, Materiali in Technologic 40 (2006) 83-88. 